\title{
On the processing of JEFF-3.2 neutron data library with AMPX 6.2 for its use with the SCALE tool suite
}

\author{
C.J. Díez ${ }^{1}$, a , F. Michel-Sendis ${ }^{1}$, O. Cabellos ${ }^{1}$, D. Wiarda², and M.E. Dunn ${ }^{2}$ \\ ${ }^{1}$ OECD Nuclear Energy Agency (NEA) - Data Bank, 92130, Issy-les-Moulineaux, France \\ ${ }^{2}$ Oak Ridge National Laboratory, Reactor and Nuclear Systems Division, 37831-6170, Oak Ridge, TN, USA
}

\begin{abstract}
New processing capabilities are under development at the NEA Data Bank (DB) that aim to provide enlarged and enhanced nuclear data services to member countries in the framework of processing, verification and benchmarking of evaluated nuclear data. Within the context of the Joint Evaluated Fission and Fusion Nuclear Data Library Project (JEFF), we undertake to generate, with the latest version of AMPX processing code, a JEFF-3.2 incident-neutron nuclear data application library for the SCALE tool suite. In this paper we describe the requirements, in terms of nuclear data content, for new data to be considered and used in the SCALE tool suite. An overview of how to process and prepare JEFF-3.2 incident-neutron data with AMPX for its application in SCALE neutron transport codes is given. The resulting library is verified and tested at differential and integral level by comparing the performance of JEFF-3.2 in AMPX format with other processing and transport codes.
\end{abstract}

\section{Introduction}

The OECD Nuclear Energy Agency (NEA) Data Bank (DB) is host to the Joint Evaluated Fission and Fusion (JEFF) Nuclear Data Library project since its creation in 1981. JEFF official releases of nuclear data are distributed in ENDF-6 format [1]. Historically, the DB has also made available processed versions of neutron cross section libraries in ACE (A Compact ENDF) format for use with Continuous Energy (CE) Monte Carlo codes such as MCNP5 [2]. These processed libraries are available upon request from NEA or freely accessible from the web, e.g. for the latest release of JEFF: JEFF-3.2 library [3].

In order to expand JEFF's user-base to include other widely used neutron transport codes, the DB has undertaken to process neutron data of JEFF-3.2, into application libraries for the SCALE tool suite [4], for criticality and shielding calculations. This task is possible thanks to the AMPX processing code release since SCALE6.2 $\beta 3$.

In this paper, we describe how JEFF-3.2 neutron data files are processed with AMPX into CE libraries. Problems encountered during processing are reported and, whenever possible, their implemented solutions. Verification tests and numerical benchmarks are performed to check correct usage of the resulting processed data. Finally, the performance of these CE libraries is assessed with a selection of criticality benchmarks used in MCNP6 validation [5].

ae-mail: carlosjavier.diez@oecd.org 


\section{Processing evaluated cross section data}

\subsection{The JEFF-3.2 neutron library}

The JEFF nuclear data library is a compilation of evaluated nuclear data files produced by a collaboration of Data Bank member countries which form the JEFF Project. The JEFF library consists in its diverse releases over the year of neutron and proton interaction data libraries, radioactive decay data libraries, fission yields, and thermal scattering law data libraries.

This work only addresses the treatment of JEFF-3.2 neutron data, which is the latest JEFF release of March 2014. The JEFF-3.2 neutron data library provides cross section data for 472 nuclides and thermal scattering libraries (TSL) for 9 different compounds in ENDF-6 formatted files.

\subsection{Processing with AMPX}

AMPX is a modular code system, developed by the Reactor and Nuclear Systems Division (RNSD) at Oak Ridge National Laboratory (ORNL), for processing ENDF-6 format evaluations into multi-group (MG) and CE cross sections using different formats that suit different particle transport codes.

In this paper, only how to generate CE cross section data is addressed. Such a task consists of generating the different parts of CE cross section data with the corresponding AMPX module:

- Point cross section data is the representation of cross section data as pairs of points $(\sigma, \mathrm{E})$, cross section values at incident particle energy respectively, and linearly interpolating between two points for incident energies not represented. Contributions from the resonance region are added if present. The Polident module creates these point-wise data, reconstructing cross section values from resonance parameters, while Broaden performs Doppler-broadening. Tgel keeps the consistency between partial and total reactions.

- Unresolved resonance data (if present) represents the energy region for incident particles where resonances are so closely spaced in energy that it is either impossible or impractical to "resolve" each resonance. As a result, unresolved resonance parameters are averaged as resolved resonance parameters over energy. They can be treated in a statistical way with Monte Carlo techniques, using the so-called "probability tables". Purm generates such probability tables from the Unresolved resonance parameters at different temperatures.

- Scattering kinematics store differential cross section data: outgoing energy particles and angles as a function of incident particle energy. $Y 12$ is used to generate kinematics data for neutron scattering and gamma-production scattering, producing double-differential data, while Jamaican converts the double differential point-wise distributions into marginal probability distributions in angle and conditional probability distributions in exit energy. The same codes are used for processing thermal scattering libraries.

An additional module, Platinum, is required for merging all the parts into final CE libraries.

\subsection{Processing JEFF-3.2 cross section data with AMPX}

The JEFF-3.2 cross section data is processed with AMPX into CE libraries and TSL for their use in SCALE transport codes. Files for ${ }^{49} \mathrm{~V}$ and ${ }^{13} \mathrm{C}$ are not considered as long as cross section files for natural isotopic compositions are given, ${ }^{n a t} \mathrm{~V}$ and ${ }^{\text {nat }} \mathrm{C}$ correspondingly. Regarding TSL, data for ${ }^{1} \mathrm{H}$ in $\mathrm{CaH}_{2}, \mathrm{Ca}$ in $\mathrm{CaH}_{2}$ and $\mathrm{Mg}$ in $\mathrm{Mg}$ metal are not processed as long as the presented bound states have not been considered nor included yet in SCALE.

Different issues arise during processing which should be reviewed, and then, communicated to evaluators if necessary: 
- Negative cross section values found when reconstructing cross sections from resonance parameters (12 isotopes): ${ }^{40} \mathrm{Ar}{ }^{141} \mathrm{Ce},{ }^{54} \mathrm{Fe},{ }^{152,157} \mathrm{Gd},{ }^{22} \mathrm{Na},{ }^{128} \mathrm{Te},{ }^{46,49,50} \mathrm{Ti},{ }^{89} \mathrm{Y}$ and ${ }^{90} \mathrm{Zr}$. Any negative cross section value obtained during reconstruction is set to zero.

- Total resonance width given in the file differs from calculated ( 3 isotopes): ${ }^{141} \mathrm{Ce},{ }^{22} \mathrm{Na}$ and ${ }^{90} \mathrm{Zr}$.

- The lower limit of the Unresolved Resonance Range (URR) does not include in its range some unresolved resonance parameters given (1 isotope): ${ }^{239} \mathrm{U}$. Parameters are interpolated in order to have values within the boundaries of URR when processed with AMPX.

- Sampling negative cross sections when generating probability tables ( 1 isotope): ${ }^{22} \mathrm{Na}$. It is not considered further in this work.

\section{Verifying the processed CE libraries from JEFF-3.2}

By verification, we mean that CE libraries generated can be used in the SCALE tool suite, and their performance in test cases are comparable with results from other codes/applications. Two different test cases are used for this purpose.

\subsection{Infinite dilution calculations}

They consist of criticality $\left(\mathrm{k}_{\text {eff }}\right)$ calculations of an infinite dilution of fissionable material $\left({ }^{235} \mathrm{U}\right.$ as default) in a solution of the nuclide whose CE data is tested. Their results show that all CE libraries generated can be used except for two isotopes: ${ }^{152 m} \mathrm{Eu}$ and ${ }^{131 m} \mathrm{Te}$. They have not yet been implemented in SCALE, in the modules where compositions and density mixtures are calculated. For the rest, the generated $\mathrm{CE}$ libraries successfully pass this test.

\subsection{Transmission calculations}

They consist in a mono-energetic and mono-directional neutron beam which impinges perpendicularly onto a slab of $25 \times 25 \times 5 \mathrm{~cm}$ of the nuclide to test, tallying the neutron spectrum behind the slab in a $2 \times 2 \times 2 \mathrm{~cm}$ cube situated $1.5 \mathrm{~cm}$ away from the slab (between the slab rear face and the cube's nearest face to the slab). The neutron energies used range from $14.0155 \mathrm{MeV}$ to $0.1125 \mathrm{eV}$. Fission events are not considered in these calculations.

The total neutron flux observed in the volume tally is compared between MCNP5 [2], using cross section data processed with NJOY2012 [6], and SCALE. Due to issues arising during calculations, the isotopes (76 in total) in Table 1 were not assessed.

For the rest, differences larger than $10 \%$ are registered for 152 isotopes (see Table 1) when the statistical uncertainty associated with results is smaller than $10 \%$. No discrepancies are found for incident neutrons at $0.1125 \mathrm{eV}$. Without probability tables, the number of isotopes with discrepancies decreases to 17 isotopes: 5 falling within statistical uncertainty, while the rest have different issues presented in Table 2.

Differences due to usage of probability tables come from the different handling of cross sections in URR during processing, where AMPX calculates values at the energy of reference and then interpolates on cross section to add additional points if needed, while NJOY calculates at the energy of reference and then interpolates on URR resonance parameters. The ENDF-6 manual says interpolation should be done on cross section. For isotopes whose cross sections are reconstructed from URR parameters, this could lead to differences between NJOY and AMPX. Also, MCNP and SCALE use probability tables in slightly different ways, especially while re-sampling cross sections in that range. In addition, differences can come from scattering data, when incident neutron energies are close to reaction thresholds which use Kalbach-Mann representation [1]. 
Table 1. Isotopes with differences between SCALE and MCNP larger than 10\% in total neutron flux tallied in the cubic volume behind the slab for different mono-energetic neutron beams transmission calculations, not considering fission reactions. Below, those isotopes which could not be compared.

\begin{tabular}{|c|c|c|c|c|c|c|c|c|c|c|}
\hline${ }^{107} \mathrm{Ag}$ & ${ }^{110 m 1} \mathrm{Ag}$ & ${ }^{242 m 1} \mathrm{Am}$ & ${ }^{36} \mathrm{Ar}$ & ${ }^{38} \mathrm{Ar}$ & ${ }^{197} \mathrm{Au}$ & ${ }^{10} \mathrm{~B}$ & ${ }^{130} \mathrm{Ba}$ & ${ }^{132} \mathrm{Ba}$ & ${ }^{133} \mathrm{Ba}$ & ${ }^{135} \mathrm{Ba}$ \\
\hline${ }^{9} \mathrm{Be}$ & ${ }^{247} \mathrm{Bk}$ & ${ }^{249} \mathrm{Bk}$ & ${ }^{106} \mathrm{Cd}$ & ${ }^{108} \mathrm{Cd}$ & ${ }^{110} \mathrm{Cd}$ & ${ }^{111} \mathrm{Cd}$ & ${ }^{112} \mathrm{Cd}$ & ${ }^{114} \mathrm{Cd}$ & ${ }^{136} \mathrm{Ce}$ & ${ }^{138} \mathrm{Ce}$ \\
\hline${ }^{139} \mathrm{Ce}$ & ${ }^{143} \mathrm{Ce}$ & ${ }^{144} \mathrm{Ce}$ & ${ }^{249} \mathrm{Cf}$ & ${ }^{250} \mathrm{Cf}$ & ${ }^{251} \mathrm{Cf}$ & ${ }^{252} \mathrm{Cf}$ & ${ }^{242} \mathrm{Cm}$ & ${ }^{246} \mathrm{Cm}$ & ${ }^{247} \mathrm{Cm}$ & ${ }^{248} \mathrm{Cm}$ \\
\hline${ }^{250} \mathrm{Cm}$ & ${ }^{133} \mathrm{Cs}$ & ${ }^{135} \mathrm{Cs}$ & ${ }^{137} \mathrm{Cs}$ & ${ }^{156}$ Dy & ${ }^{158}$ Dy & ${ }^{160}$ Dy & ${ }^{161}$ Dy & ${ }^{162}$ Dy & ${ }^{163}$ Dy & ${ }^{164}$ Dy \\
\hline${ }^{253}$ Es & ${ }^{151} \mathrm{Eu}$ & ${ }^{152} \mathrm{Eu}$ & ${ }^{153} \mathrm{Eu}$ & ${ }^{154} \mathrm{Eu}$ & ${ }^{155} \mathrm{Eu}$ & ${ }^{156} \mathrm{Eu}$ & ${ }^{157} \mathrm{Eu}$ & ${ }^{58} \mathrm{Fe}$ & ${ }^{69} \mathrm{Ga}$ & ${ }^{71} \mathrm{Ga}$ \\
\hline${ }^{152} \mathrm{Gd}$ & ${ }^{153} \mathrm{Gd}$ & ${ }^{154} \mathrm{Gd}$ & ${ }^{155} \mathrm{Gd}$ & ${ }^{156} \mathrm{Gd}$ & ${ }^{70} \mathrm{Ge}$ & ${ }^{72} \mathrm{Ge}$ & ${ }^{74} \mathrm{Ge}$ & ${ }^{174} \mathrm{Hf}$ & ${ }^{176} \mathrm{Hf}$ & ${ }^{177} \mathrm{Hf}$ \\
\hline${ }^{178} \mathrm{Hf}$ & ${ }^{179} \mathrm{Hf}$ & ${ }^{180} \mathrm{Hf}$ & ${ }^{166 m 1} \mathrm{Ho}$ & ${ }^{127} \mathrm{I}$ & ${ }^{131} \mathrm{I}$ & ${ }^{113} \mathrm{In}$ & ${ }^{193} \mathrm{Ir}$ & ${ }^{39} \mathrm{~K}$ & ${ }^{78} \mathrm{Kr}$ & ${ }^{80} \mathrm{Kr}$ \\
\hline${ }^{82} \mathrm{Kr}$ & ${ }^{84} \mathrm{Kr}$ & ${ }^{138} \mathrm{La}$ & ${ }^{140} \mathrm{La}$ & ${ }^{176} \mathrm{Lu}$ & ${ }^{55} \mathrm{Mn}$ & ${ }^{143} \mathrm{Nd}$ & ${ }^{144} \mathrm{Nd}$ & ${ }^{145} \mathrm{Nd}$ & ${ }^{146} \mathrm{Nd}$ & ${ }^{147} \mathrm{Nd}$ \\
\hline${ }^{148} \mathrm{Nd}$ & ${ }^{232} \mathrm{~Pa}$ & ${ }^{107} \mathrm{Pd}$ & ${ }^{110} \mathrm{Pd}$ & ${ }^{147} \mathrm{Pm}$ & ${ }^{148} \mathrm{Pm}$ & ${ }^{149} \mathrm{Pm}$ & ${ }^{151} \mathrm{Pm}$ & ${ }^{141} \mathrm{Pr}$ & ${ }^{143} \mathrm{Pr}$ & ${ }^{236} \mathrm{Pu}$ \\
\hline${ }^{238} \mathrm{Pu}$ & ${ }^{225} \mathrm{Ra}$ & ${ }^{105} \mathrm{Rh}$ & ${ }^{101} \mathrm{Ru}$ & ${ }^{34} \mathrm{~S}$ & ${ }^{45} \mathrm{Sc}$ & ${ }^{74} \mathrm{Se}$ & ${ }^{76} \mathrm{Se}$ & ${ }^{77} \mathrm{Se}$ & ${ }^{78} \mathrm{Se}$ & ${ }^{80} \mathrm{Se}$ \\
\hline${ }^{82} \mathrm{Se}$ & ${ }^{144} \mathrm{Sm}$ & ${ }^{147} \mathrm{Sm}$ & ${ }^{148} \mathrm{Sm}$ & ${ }^{149} \mathrm{Sm}$ & ${ }^{150} \mathrm{Sm}$ & ${ }^{151} \mathrm{Sm}$ & ${ }^{152} \mathrm{Sm}$ & ${ }^{153} \mathrm{Sm}$ & ${ }^{154} \mathrm{Sm}$ & ${ }^{112} \mathrm{Sn}$ \\
\hline${ }^{116} \mathrm{Sn}$ & ${ }^{118} \mathrm{Sn}$ & ${ }^{119} \mathrm{Sn}$ & ${ }^{122} \mathrm{Sn}$ & ${ }^{124} \mathrm{Sn}$ & ${ }^{84} \mathrm{Sr}$ & ${ }^{86} \mathrm{Sr}$ & ${ }^{89} \mathrm{Sr}$ & ${ }^{90} \mathrm{Sr}$ & ${ }^{182} \mathrm{Ta}$ & ${ }^{160} \mathrm{~Tb}$ \\
\hline${ }^{122} \mathrm{Te}$ & ${ }^{124} \mathrm{Te}$ & ${ }^{170} \mathrm{Tm}$ & ${ }^{240} \mathrm{U}$ & ${ }^{182} \mathrm{~W}$ & ${ }^{183} \mathrm{~W}$ & ${ }^{184} \mathrm{~W}$ & ${ }^{186} \mathrm{~W}$ & ${ }^{128} \mathrm{Xe}$ & ${ }^{129} \mathrm{Xe}$ & ${ }^{132} \mathrm{Xe}$ \\
\hline${ }^{133} \mathrm{Xe}$ & ${ }^{91} \mathrm{Y}$ & ${ }^{64} \mathrm{Zn}$ & ${ }^{66} \mathrm{Zn}$ & ${ }^{68} \mathrm{Zn}$ & ${ }^{70} \mathrm{Zn}$ & ${ }^{90} \mathrm{Zr}$ & ${ }^{92} \mathrm{Zr}$ & ${ }^{94} \mathrm{Zr}$ & & \\
\hline
\end{tabular}

Failed to run in MCNP (x10):

\begin{tabular}{ccccccccccc}
\hline${ }^{31} \mathrm{P}$ & ${ }^{62} \mathrm{Ni}$ & ${ }^{76} \mathrm{Ge}$ & ${ }^{109} \mathrm{Ag}$ & ${ }^{115} \mathrm{In}$ & ${ }^{134} \mathrm{Cs}$ & ${ }^{162} \mathrm{Er}$ & ${ }^{187} \mathrm{Re}$ & ${ }^{233} \mathrm{Th}$ & ${ }^{242} \mathrm{Am}$ & \\
\hline \multicolumn{7}{l}{ Failed to run in SCALE (x66): } \\
\hline${ }^{39} \mathrm{Ar}$ & ${ }^{41} \mathrm{Ar}$ & ${ }^{139} \mathrm{Ba}$ & ${ }^{41} \mathrm{Ca}$ & ${ }^{45} \mathrm{Ca}$ & ${ }^{109} \mathrm{Cd}$ & ${ }^{36} \mathrm{Cl}$ & ${ }^{57} \mathrm{Co}$ & ${ }^{60} \mathrm{Co}$ & ${ }^{51} \mathrm{Cr}$ & ${ }^{64} \mathrm{Cu}$ \\
${ }^{66} \mathrm{Cu}$ & ${ }^{165} \mathrm{Dy}$ & ${ }^{169} \mathrm{Er}$ & ${ }^{171} \mathrm{Er}$ & ${ }^{172} \mathrm{Er}$ & ${ }^{148} \mathrm{Gd}$ & ${ }^{161} \mathrm{Gd}$ & ${ }^{181} \mathrm{Hf}$ & ${ }^{126} \mathrm{I}$ & ${ }^{128} \mathrm{I}$ & ${ }^{192} \mathrm{Ir}$ \\
${ }^{177} \mathrm{Lu}$ & ${ }^{27} \mathrm{Mg}$ & ${ }^{53} \mathrm{Mn}$ & ${ }^{54} \mathrm{Mn}$ & ${ }^{20} \mathrm{Ne}$ & ${ }^{21} \mathrm{Ne}$ & ${ }^{22} \mathrm{Ne}$ & ${ }^{63} \mathrm{Ni}$ & ${ }^{18} \mathrm{O}$ & ${ }^{184} \mathrm{Os}$ & ${ }^{186} \mathrm{Os}$ \\
${ }^{205} \mathrm{~Pb}$ & ${ }^{209} \mathrm{Po}$ & ${ }^{190} \mathrm{Pt}$ & ${ }^{192} \mathrm{Pt}$ & ${ }^{187} \mathrm{Os}$ & ${ }^{188} \mathrm{Os}$ & ${ }^{189} \mathrm{Os}$ & ${ }^{190} \mathrm{Os}$ & ${ }^{191} \mathrm{Os}$ & ${ }^{192} \mathrm{Os}$ & ${ }^{193} \mathrm{Os}$ \\
${ }^{194} \mathrm{Pt}$ & ${ }^{195} \mathrm{Pt}$ & ${ }^{196} \mathrm{Pt}$ & ${ }^{198} \mathrm{Pt}$ & ${ }^{88} \mathrm{Rb}$ & ${ }^{188} \mathrm{Re}$ & ${ }^{104} \mathrm{Rh}$ & ${ }^{46} \mathrm{Sc}$ & ${ }^{31} \mathrm{Si}$ & ${ }^{32} \mathrm{Si}$ & ${ }^{180 m 1} \mathrm{Ta}$ \\
${ }^{98} \mathrm{Tc}$ & ${ }^{204} \mathrm{Tl}$ & ${ }^{171} \mathrm{Tm}$ & ${ }^{168} \mathrm{Yb}$ & ${ }^{169} \mathrm{Yb}$ & ${ }^{170} \mathrm{Yb}$ & ${ }^{171} \mathrm{Yb}$ & ${ }^{172} \mathrm{Yb}$ & ${ }^{173} \mathrm{Yb}$ & ${ }^{174} \mathrm{Yb}$ & ${ }^{176} \mathrm{Yb}$ \\
\hline
\end{tabular}

Table 2. Summary of sources for issues on isotopes in Table 1 when probabliy tables are not used.

\begin{tabular}{rrcl}
\hline Isotope & Energy & Region & Issue \\
\hline${ }^{107} \mathrm{Ag}$ & $1.10 \mathrm{keV}$ & $\mathrm{RRR} \rightarrow$ Fast & Different amount of interpolation points in AMPX and NJOY \\
${ }^{197} \mathrm{Au}$ & $9.86 \mathrm{keV}$ & URR & AMPX issue using scattering radius as function of energy (corrected) \\
${ }^{9} \mathrm{Be}$ & $>3.87 \mathrm{MeV}$ & - & AMPX cannot handle (n,2n + excited residual) reactions (MT875+) \\
${ }^{247} \mathrm{Bk}$ & $1.10 \mathrm{keV}$ & $\mathrm{RRR} \rightarrow$ Fast & Different amount of interpolation points in AMPX and NJOY \\
${ }^{253} \mathrm{Es}$ & $90.1 \mathrm{eV}$ & $\mathrm{RRR}$ & Discrepancies in RRR reconstruction, difference within statistical uncertainty \\
${ }^{154} \mathrm{Gd}$ & $9.86 \mathrm{keV}$ & $\mathrm{URR}$ & AMPX and NJOY generate different average cross section values in URR \\
${ }^{147} \mathrm{Nd}$ & $1.10 \mathrm{keV}$ & URR & AMPX and NJOY generate different average cross section values in URR \\
${ }^{236} \mathrm{Pu}$ & $90.1 \mathrm{eV}$ & URR & AMPX and NJOY generate different average cross section values in URR \\
${ }^{225} \mathrm{Ra}$ & $90.1 \mathrm{eV}$ & $10-100 \mathrm{eV}$ & Integral cross section value differs 0.6\% and close to statistical uncertainty \\
${ }^{45} \mathrm{Sc}$ & $104 \mathrm{keV}$ & - & ENDF-6 evaluation provides two cross section values at 100 keV \\
${ }^{150} \mathrm{Sm}$ & $2.94 \mathrm{MeV}$ & Fast & Origin not found (probable issue with differential cross section) \\
${ }^{90} \mathrm{Zr}$ & $104 \mathrm{keV}$ & RRR & Different treatment of total width in RRR between AMPX and NJOY \\
\hline
\end{tabular}

\section{Benchmarking the processed CE libraries from JEFF-3.2 for criticality}

The processed libraries are benchmarked, comparing $\mathrm{k}_{\mathrm{eff}}$ from SCALE6.2b3 and MCNP6.1 results [7]. The benchmarks to calculate are selected, due to input availability in both codes, from those in the criticality validation suite for MCNP6 [5], shown in Table 3 using the ICSBEP identifiers [8]. 
Results are presented in Table 3, marked in grey those cases where SCALE and MCNP $\mathrm{k}_{\mathrm{eff}}$ values differ more than $60 \mathrm{pcm}$. The source of differences for the highlighted cases are discussed:

- HEU-COMP-INTER-003-006 (82 pcm) whose difference comes partially from ${ }^{197} \mathrm{Au}$, due to differences in reconstruction of ${ }^{197} \mathrm{Au}$ cross sections in URR. However, not including ${ }^{197} \mathrm{Au}$ in calculations yields a difference between MCNP and SCALE of $154 \mathrm{pcm}$, so the equivalence of MCNP and SCALE models shall be checked.

- HEU-MET-FAST-026-021 (93 pcm) has differences between in MCNP and SCALE models, such as the amount of paraffin. Once equaled, the difference increases up to $343 \mathrm{pcm}$. Model representations in both cases shall be reviewed.

- U233-COMP-THERM-001-003 (204 pcm) has ${ }^{90} \mathrm{Zr}$ in its composition, for which large discrepancies have been observed in transmission tests. It has a large impact in $\mathrm{k}_{\text {eff }}$ as seen from sensitivity analysis, so when it is not included in calculations, differences are reduced to $23 \mathrm{pcm}$.

- U233-MET-FAST-005-002 (2210 pcm) is a ${ }^{233} \mathrm{U}$ sphere reflected by ${ }^{9} \mathrm{Be}$ which involves fast neutron spectrum. As seen in transmission cases, large differences will be encountered using ${ }^{9} \mathrm{Be}$ due to issues in handling MT875+ reaction channels with AMPX.

Therefore, despite HEU-COMP-INTER-003-006 and HEU-MET-FAST-026-021 cases where equivalence between MCNP and SCALE models shall be reviewed, a good agreement is achieved between MCNP and SCALE processing the JEFF-3.2 neutron cross section libraries with AMPX and NJOY.

Table 3. Results for $\mathrm{k}_{\text {eff }}$ in criticality benchmarks using SCALE6.2b3 and MCNP6.1, marked in grey are those with differences between MCNP and SCALE larger than $60 \mathrm{pcm}$.

\begin{tabular}{lllllllr}
\hline & \multicolumn{2}{c}{ Experiments } & \multicolumn{2}{c}{ MCNP6.1 } & \multicolumn{2}{c}{ SCALE6.2b3 } & Diff. \\
Identifier & $\mathrm{k}_{\text {eff }}$ & unc. & $\mathrm{k}_{\text {eff }}$ & unc. & $\mathrm{k}_{\text {eff }}$ & unc. & (pcm) \\
\hline HEU-COMP-INTER-003-006 & 1.00000 & 0.00470 & 0.99793 & 0.00003 & 0.99875 & 0.000027 & -82 \\
HEU-MET-FAST-026-021 & 1.00000 & 0.00380 & 0.99885 & 0.00002 & 0.99792 & 0.000099 & 93 \\
HEU-MET-FAST-028-001 & 1.00000 & 0.00300 & 1.00502 & 0.00002 & 1.00539 & 0.000035 & -37 \\
HEU-SOL-THERM-032-001 & 1.00150 & 0.00260 & 0.99903 & 0.00002 & 0.99908 & 0.000041 & -5 \\
IEU-MET-FAST-003-001 (Detailed) & 1.00000 & 0.00170 & 1.00245 & 0.00002 & 1.00289 & 0.000099 & -44 \\
IEU-MET-FAST-004-001 (Detailed) & 1.00000 & 0.00300 & 1.00705 & 0.00002 & 1.00748 & 0.000091 & -43 \\
LEU-COMP-THERM-008-002 & 1.00070 & 0.00120 & 1.00069 & 0.00005 & 1.00019 & 0.00005 & 50 \\
LEU-SOL-THERM-002-002 & 1.00240 & 0.00370 & 0.99618 & 0.00002 & 0.99582 & 0.000099 & 36 \\
LEU-SOL-THERM-007-004 & 0.99880 & 0.00110 & 0.99898 & 0.00002 & 0.99838 & 0.000043 & 60 \\
MIX-COMP-THERM-002-004 & 1.00240 & 0.00240 & 1.00679 & 0.00002 & 1.00693 & 0.000097 & -14 \\
PU-COMP-INTER-001-001 & 1.00000 & 0.01100 & 1.00603 & 0.00002 & 1.00612 & 0.000073 & -9 \\
PU-MET-FAST-001-001 (Detailed) & 0.99999 & 0.00129 & 1.00021 & 0.00002 & 1.00056 & 0.000029 & -35 \\
PU-MET-FAST-002-001 & 1.00000 & 0.00200 & 1.00258 & 0.00002 & 1.00296 & 0.000099 & -38 \\
PU-MET-FAST-003-003 & 1.00000 & 0.00300 & 0.99679 & 0.00002 & 0.99666 & 0.000063 & 13 \\
PU-MET-FAST-006-001 & 1.00000 & 0.00300 & 1.00218 & 0.00002 & 1.00262 & 0.000099 & -44 \\
PU-MET-FAST-011-001 & 1.00000 & 0.00100 & 0.99786 & 0.00002 & 0.99795 & 0.00011 & -9 \\
U233-COMP-THERM-001-003 & 1.00000 & 0.00240 & 1.00288 & 0.00002 & 1.00493 & 0.0001 & -204 \\
U233-MET-FAST-001-001 & 1.00000 & 0.00100 & 0.99985 & 0.00002 & 1.00008 & 0.000099 & -23 \\
U233-MET-FAST-005-002 & 1.00000 & 0.00300 & 0.99515 & 0.00002 & 0.97363 & 0.000026 & 2210 \\
U233-MET-FAST-006-001 & 1.00000 & 0.00140 & 1.0008 & 0.00002 & 1.00123 & 0.000049 & -43 \\
\hline
\end{tabular}




\section{Conclusions}

The JEFF-3.2 neutron cross section library has been processed with the AMPX version released in SCALE6.2b4. A continuous energy library for neutrons is generated for its use with SCALE transport calculations tools: KENO for criticality and MAVRIC-MONACO for shielding.

This work has identified different issues to address during the processing of JEFF-3.2 data with AMPX, which concern 17 isotopes (see Sec. 2.3). Those issues which are more relevant due to their impact in benchmarking are due to ${ }^{22} \mathrm{Na}$ and ${ }^{90} \mathrm{Zr}$. Therefore, for these 17 isotopes, processing and evaluations shall be reviewed.

The verification of processed files is carried out by performing criticality calculations in infinite dilution cases and transmission tests. These tests show the need to implement the definition of some isotopes in SCALE: ${ }^{152 m} \mathrm{Eu},{ }^{180 m} \mathrm{Ta}$ and ${ }^{131 m} \mathrm{Te}$, as well as those marked in Table 1 for transmission tests. When comparing SCALE and MCNP results in transmissions tests, large differences were found for 150 isotopes (Table 1), due to a different treatment of the URR in processing and its usage in transport codes. The number of discrepant isotopes sharply decreases when probability tables are not used, where important differences are only found for 12 isotopes, with their likely issues being described in Table 2.

Finally, the generated CE library from JEFF-3.2 is used in a selection of benchmarks from the criticality validation suite for MCNP6. A comparison of SCALE and MCNP results is given. In general, a good agreement is obtained, within $60 \mathrm{pcm}$ differences except for 4 cases. For 3 of these 4 cases, isotopes with large differences found in transmission tests are involved, such as ${ }^{197} \mathrm{Au},{ }^{9} \mathrm{Be}$ and ${ }^{90} \mathrm{Zr}$. The differences found are however not completely explained, and would require the further review of both the MCNP and SCALE input models used.

Once the missing isotopes have been implemented in SCALE libraries, further study on transmission tests should be carried out with a wider selection of benchmarks in order to expand the application cases. Although, this latter work depends also in availability of inputs, for which checks on equivalence shall carried out.

This work has focused on processing the entire JEFF-3.2 neutron data library with the AMPX version released in SCALE6.2b4. Although most of the evaluations are processed successfully, the goal of releasing the thoroughly processed CE library from JEFF-3.2 library for SCALE would still need some necessary actions and decisions to be taken and which concern the issues mentioned. Nevertheless, this work has set the first milestones and established a successful collaboration for the future usage of JEFF libraries within SCALE.

\section{References}

[1] CSEWG, Tech. Rep. BNL-90365-2009 Rev.2, BNL (2012)

[2] X-5 Monte Carlo Team, Tech. Rep. LA-CP-03-0245, LANL (2003), Version 5

[3] OECD/NEA Data Bank, JEFF-3.2 Evaluated Data Library - Neutron data (2014), http: //www . oecd-nea.org/dbforms/data/eva/evatapes/jeff_32/

[4] ORNL, SCALE: A comprehensive modeling and simulation suite for nuclear safety analysis and design (2011), ORNL/TM-2005/39, Version 6.1

[5] R.D. Mosteller, Tech. Rep. LA-UR-02-0878, LANL (2002)

[6] R.E. MacFarlane, D.W. Muir, R.M. Boicourt, A.C. Kahler, Tech. Rep. LA-UR-12-27079, LANL (2015)

[7] T. Goorley, M. James, T. Booth, F. Brown, J. Bull, L. Cox, J. Durkee, J. Elson, M. Fensin, R. Forster et al., Nuclear Technology 180, 298 (2012)

[8] J.B.B. editor, Tech. Rep. NEA/NSC/DOC(95)03, OECD Nuclear Energy Agency (2010) 